\title{
Identification of Quantitative Trait Loci responsible for embryonic lethality in mice assessed by ultrasonography
}

\author{
PAUL LAISSUE ${ }^{1,2,3}$, GAÉTAN BURGIO ${ }^{4}$, DAVID L'HÔTE1,2,3,5, GILLES RENAULT ${ }^{1,2,3}$ \\ CARMEN MARCHIOL-FOURNIGAULT1,2,3, DIDIER FRADELIZI 1,2,3, MARC FELLOUS 1,2,3, CATHERINE SERRES ${ }^{1,2,3}$, \\ XAVIER MONTAGUTELLI ${ }^{4}$, PHILIPPE MONGET ${ }^{6}$ and DANIEL VAIMAN* ${ }^{*}, 1,2,3,7$. \\ 'INSERM, U567, Institut Cochin, Paris, ${ }^{2}$ CNRS, UMR8104, Institut Cochin, Paris, ${ }^{3}$ Université Paris Descartes, Faculté de Médecine Hôpital \\ Cochin, Paris, ${ }^{4}$ Institut Pasteur, Unité de Génétique des Mammifères, Paris, ${ }^{5}$ INRA/Université de Limoges, UMR 1061, Unité de \\ Génétique Moléculaire Animale, Université de Limoges, Limoges, 6 INRA - CNRS - Université de Tours - Haras Nationaux, Nouzilly and \\ ${ }^{7}$ INRA, Department of Animal Genetics, Jouy-en-Josas, France.
}

\begin{abstract}
Recurrent Spontaneous Abortion (RSA) is a frequent pathology affecting $\mathbf{1}$ to $5 \%$ of couples. In $\sim 50 \%$ of cases, the aetiology is unknown suggesting a subtle interaction between genetic and environmental factors. Previous attempts to describe genetic factors using the candidate gene approach have been relatively unsuccessful due to the physiological, cellular and genetic complexity of mammalian reproduction. Indeed, fertility can be considered as a quantitative feature resulting from the interaction of genetic, epigenetic and environmental factors. Herein, we identified Quantitative Trait Loci (OTL) associated with diverse embryonic lethality phenotypes and the subsequent embryonic resorption in 39 inter-specific recombinant congenic mice strains, using in vivo ultrasound bio-microscopy. The short chromosomal intervals related to the phenotypes will facilitate the study of a restricted number of candidate genes which are potentially dysregulated in patients affected by RSA.
\end{abstract}

KEY WORDS: resorption, ultrasound biomicroscopy, quantitative trait loci, recurrent spontaneous abortion

\section{Introduction}

Reproduction in placental mammals involves the harmonious action of several subtly regulated physiological, molecular and cellular processes, implicating complex successive developmental stages from egg fertilization to foetus delivery. One of the first "challenges" encountered by the zygote occurs during the preimplantation period, when the maternal/zygotic transition switches expression from maternal oocyte-stored mRNA to expression from the embryo genome and activation of genes unexpressed in the oocyte (Schultz, 2002). This transition is observed at the twocell stage and between the four/eight cell stages in rodents and human, respectively (Artley etal., 1992). After this critical stage of embryonic genome activation, necessary for the blastocyst formation and its initial growth, the implantation involves the close mingling of two genetically different organisms. In order to prevent the rejection of the embryonic hemi-allograft an "immunological conciliation" has therefore to be installed. In rodents the hormonal effect of estrogens and progesterone is crucial for the preparation of the receptive uterus, during the implantation window (Huet-
Hudson etal., 1989). The oestrogen metabolites are necessary to activate the blastocyst (Paria et al., 1998) and a complex molecular dialogue is established between the blastocyst and the maternal uterine luminal epithelium. This complex interaction includes various factors, such as steroid hormones, adhesion molecules, extracellular matrix proteases, vasoactive and growth factors, cytokines and developmental genes (Dey et al., 2004, Lim et al., 2002, Wang and Dey, 2006). In eutherian mammals dysregulation in preimplatation, implantation or early postimplantation pathways have been associated with embryonic lethality and infertility, especially in mouse models where specific genes have been invalidated (Dey et al., 2004, Sharma et al., 2006, Wang and Dey, 2006). Nevertheless, the embryonic death can also occur at any postimplantation developmental stage, during organogenesis

\footnotetext{
Abbreviations used in this paper: EED, early embryonic death; ELR, embryonic lethal rate; IRCS, interspecific recombinant congenic strains; MMU, Mus Musculus chromosome; QTL, quantitative trait loci; RSA, recurrent spontaneous abortion.
} 
and foetal life, as suggested by the invalidation of numerous genes having a strong impact on fertility (http:// www.informatics.jax.org http).

Molecular understanding of embryonic implantation and development is of particular interest for the study of human infertility. For instance, miscarriage constitutes a frequent pregnancy complication representing at least $15 \%$ of medically followed pregnancies (Rai and Regan, 2006, Wilcox etal., 1988). Sporadic abortion affects $25-50 \%$ of couples, while recurrent spontaneous abortion (RSA), defined as at least two or 3 consecutive pregnancy losses, affects 1 to $5 \%$ of couples (Rai and Regan, 2006). The diverse aetiologies associated with RSA, include chromosomal alterations (Stephenson et al., 2002), maternal and foetal structural abnormalities (Philipp etal., 2003, Salim etal., 2003), thrombophilic disorders (Rey et al., 2003) and autoimmune disorders such as the antiphospholipid syndrome (Levine et al., 2002). Nevertheless, in $\sim 50 \%$ of the cases the aetiology remains unknown (Li et al., 2002, Plouffe et al., 1992; Tulppala etal., 1993), indicating that the underlying aetiological grounds constitute a complex lattice of genetic and environmental causes. Previous attempts to describe genetic factors using the candidate gene approach have been relatively unsuccessful (Kaare et al., 2006, Kaare et al., 2007). These disappointing results can be explained, as briefly exposed above, by the physiological, cellular and genetic complexity of every step in mammalian reproduction. Indeed, fertility can be considered as a quantitative feature resulting from the interaction of genetic, epigenetic and environmental factors. In humans, the study of the molecular actors involved in the loss of pregnancy is particularly challenging due to obvious ethical constraints, which strengthens the importance of mice models.

In this study, we aimed at identifying Quantitative Trait Loci (QTL) associated with embryonic lethality and the subsequent embryonic resorption. For this purpose, we used an original mice model of 53 Interspecific Recombinant Congenic S- trains (IRCS), each of them containing around of $2 \%$ of Mus spretus genome stably fixed at a homozygous state in a C57BL/6J genetic background (Burgio et al., 2007, L'Hote et al., 2007, Montagutelli and Abitbol, 2004). This model permits the unambiguous mapping of relevant genes into small chromosomal intervals since the spretus fragments have recently been precisely mapped using $\sim 800$ informative markers. Postimplantation embryo development, from E8.5 to E14.5 of IRCS females crossed with C57BL/6J males was

TABLE 1

C57BL/6J (CONTROL GROUP), IRCS AND SUBSTRAINS AFFECTED BY EMBRYONIC LETHALITY

\begin{tabular}{ccc} 
Strain & TNA & ETN \\
\hline C57/BL6 (parent) & 22 & 195 \\
IRCS (whole set) & 207 & 1603 \\
66H & 9 & 76 \\
$66 \mathrm{H}-\mathrm{MMU1}$ & 8 & 69 \\
66H-MMU13 & 20 & 177 \\
66H-MMU18 & 7 & 60 \\
$66 \mathrm{H}-\mathrm{MMU13+18}$ & 9 & 66 \\
103C & 6 & 51 \\
135B & 6 & 48 \\
135E & 5 & 43 \\
\hline
\end{tabular}

TNA: total number of animals examined (mothers). ETN: total number of embryos followed. assessed in vivo, using high resolution ultrasound biomicroscopy. We identified 3 QTL, located on MMU1, MMU13 and MMU19 responsible of embryonic lethality. The study of the mouse gene composition in the spretus fragments suggested several genes putatively involved in the phenotypes. The human orthologues constitute interesting targets that could be molecularly evaluated as candidates for Recurrent Spontaneous Abortion.

\section{Results and Discussion}

\section{Embryonic death phenotypes are reliably revealed by ul- trasound biomicroscopy}

In order to identify QTL related with embryonic death we examined 207 pregnant mice from 39 out of 53 available IRCS and from a control group consisting of 22-C57BL/6J animals (Table 1). The gestation was obtained by crossing each IRCS female with a C57BL/6J male, in order to maintain a constant paternal genetic background. Genetically the maternal uterine tissue is of IRCS type, while the placenta is heterozygous (B6/ SEG) at the position of the spretus segment. This design allows the detection of specifically maternal phenotypic traits inducing embryonic lethality. The defects can theoretically be due to dysregulations of uterine and/or placental genes. Females from the control group were crossed with C57BL/6J males. Embryonic development between $\mathrm{E} 8.5$ and $\mathrm{E} 14.5$ was followed in vivo on a total of 1603 heterozygous (C57BL/6J / spretus) embryos using high frequency ultrasound biomicroscopy (Table 1). This systematic ultrasonographic observation is based upon a high frequency ultrasound device, which represents an advantageous imaging modality for in vivo and non-invasive analysis of mouse embryo development (Foster et al., 2000), including functional parameters as arterial and venous flow measurements inside the umbilical cord by pulse Doppler. In accordance with ethical rules on animal experimentation, this approach considerably reduces the number of the sacrificed animals and makes it possible to carry out longitudinal studies.

Each IRCS and C57BL/6J female was also subjected to a pre-gestation ultrasonographic examination (US1) in order to evaluate putative anatomical malformations of the reproductive (vagina, uterine horns and ovaries) and urinary tracts (bladder and kidney) and to investigate signs related with local or systemic pathologies. These observations allowed us to exclude 3 individuals presenting a severe loose of kidney tissue and its replacement by a non-echogenic content, suggesting a hydronephrotic process (data not shown). Furthermore, in one individual, we could not observe uterine horn structures owing possibly to a low diameter of these structures $(<0.5 \mathrm{~mm}$, below the detection capacities of the equipment). This animal was mated several times but never became pregnant. Dissection confirmed the presence of hypoplasic uterine horns characterised by a thin and brittle tissue.

Overall, we performed a total of 1581 ultrasonographic examinations from pregnant (US2 and US3) and non-pregnant (US1) animals, including the test group. In accordance with similar studies (Ji and Phoon, 2005), these analyses enabled us to establish a perfect correlation between the total embryo number observed by ultrasonography and their presence in the uterine horns, verified after the animal dissection. The sensibility of the technique permitted us to identify and count unam- 
biguously the implanted embryos from E7.5. However, we did not examine pregnant mice before E8.5 since before this developmental stage it was difficult to distinguish living embryos and resorbed structures (Figure 1A-C). The living status of the embryo was determined by the visualisation of heartbeats and by assessment of blood flows in the umbilical cord, using pulsed Doppler mode.

Phenotypically, the dead embryos were classified into two categories (see Figure 1): early embryonic death (EED, embryo totally resorbed at US2) and late embryonic death (LED, death observed during US2 or US3, when visible organs were progressively resorbed). Nevertheless, this apparent dichotomised classification could also be considered as embryonic lethality as a whole (EL) (see below).

In most cases, in embryos of the EED phenotype, the amniotic and exocoelomic cavities were never observed (Figure 1G). At US2, by contrast, contiguous embryos displayed a normal development. Furthermore, in EED embryonic resorptions, the cardiac heartbeat, normally detected by ultrasonography from E8.5-E9.5, was absent, indicating that the EED occur mainly between embryo implantation (E4.5) and the onset of the heartbeats (E8.5). Embryonic resorption (ER) displayed a characteristic high central echogenic zone corresponding to the embryo implantation site (Figure $1 \mathrm{G}$ ).

Embryos presenting the LED phenotype displayed a heartbeat arrest and an absence of umbilical cord flow (as assessed by Doppler) visible at US3. Alternatively, they also corresponded to US2 observations of dead embryos with a clear organogenesis (a well-formed, non beating heart). In these embryos, intra-embryonic structures displayed initially a normal anatomical aspect including thoracic and abdominal viscera development similar to the surrounding embryos that
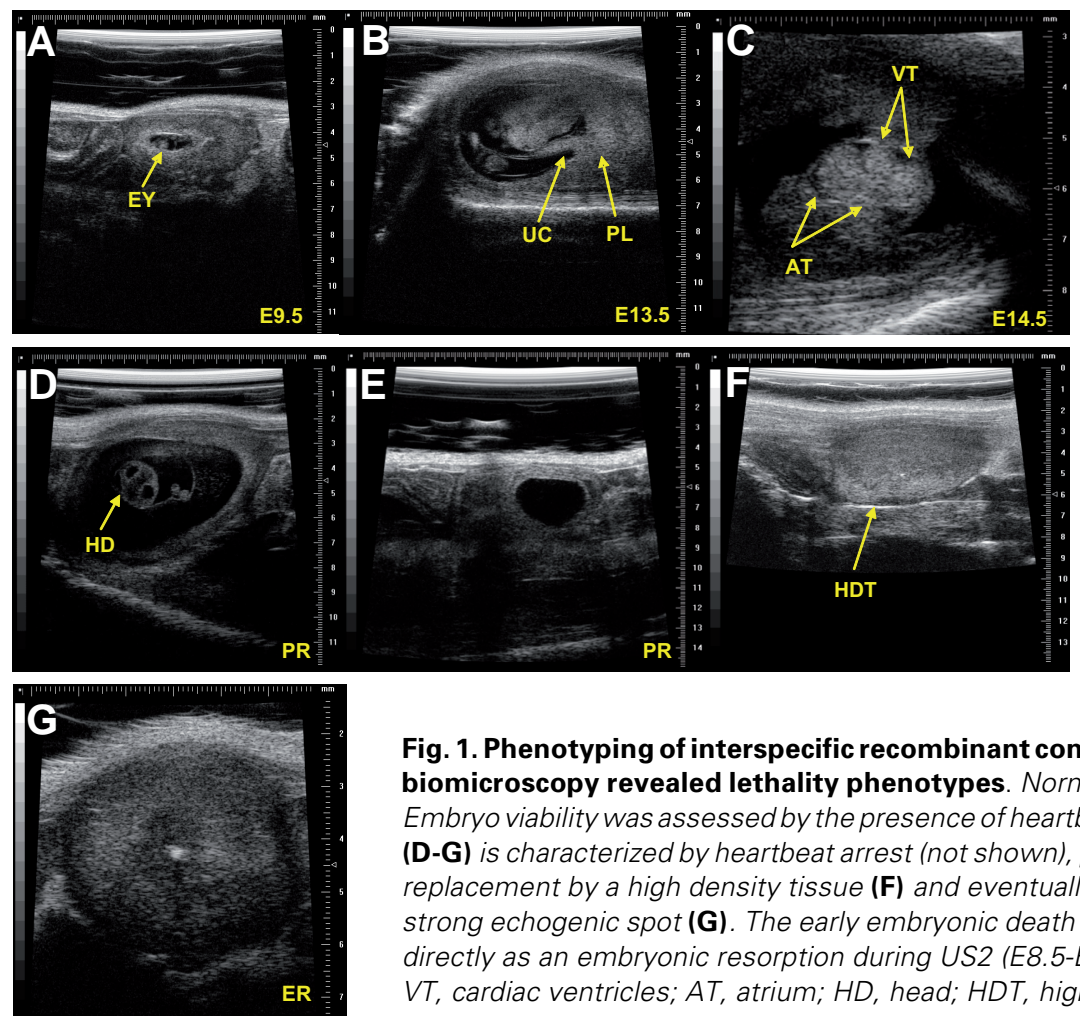

Fig. 1. Phenotyping of interspecific recombinant congenic strain (IRCS) embryo development using ultrasound biomicroscopy revealed lethality phenotypes. Normal embryo development at E9.5 (A), E13.5 (B) and E14.5 (C). Embryo viability was assessed by the presence of heartbeats and a positive umbilical cord Doppler. The LED phenotype (D-G) is characterized by heartbeat arrest (not shown), progressive resorption (PR) of the embryonic structures (D,E), replacement by a high density tissue (F) and eventually, by the general feature of final embryonic resorption (ER), a strong echogenic spot (G). The early embryonic death (EED) phenotype does not involve these phases as it appears directly as an embryonic resorption during US2 (E8.5-E12.5, Fig. 1G). EY, embryo; PL, placenta; UC, umbilical cord; $V T$, cardiac ventricles; $A T$, atrium; $H D$, head; HDT, high density tissue. would accomplish a normal development to birth. Embryos affected by LED showed a characteristic 5-step involution pathway leading, in fine, to ER (Figure 1A-G). After the first step of the LED (the heartbeat arrest), the embryonic structures became disorganised and disappeared progressively. During this step an intensive proteolytic activity probably took place the intra-embryonic structures were eventually totally completely resorbed leading to the apparition of an anechogenic cavity full of liquid (steps 2-3, Figures 1D-E). The two remaining steps of the LED pathway include the liquid replacement by a dense tissue (Step 4, Figure 1F) and finally the complete ER (step 5, Figure 1G). These findings represent the first in vivo real time description of the involution of mice defective embryos.

\section{Four interspecific recombinant congenic strains (IRCS)} tively 1603 and 195 embryos from IRCS and C57BL/6J (control group) pregnant mice. There was a perfect correlation between the total number of implanted embryo observed at US2 and 3, showing that structures are highly reliably detected, and played vidual, including EED and LED structures (Table 2 ). This result was not significantly different from the average calculated using the total number of heterozygous embryos implanted in the IRCS $(8.2 \pm 1.9)$. Among the 39 IRCS studied, we identified 4 strains $(66 \mathrm{H}, 103 \mathrm{C}, 135 \mathrm{~B}$ and $135 \mathrm{E})$ displaying a highly significant increase in embryonic lethality ratio (ELR-defined as the proportion of dead embryos at any stage of development relative to the totality of the implanted embryos), compared with the control group (results from the statistical analysis are summarized in Table 2 and Figure 2). Indeed, while the ELR in C57BL/6J was estimated at $4.6 \%$, the $66 \mathrm{H}, 103 \mathrm{C}, 135 \mathrm{~B}$ and $135 \mathrm{E}$ strains showed an increase to respectively, $14.5 \%(p=0.025), 19.6 \%(p=0.0012), 25 \%(p=$ $0.0002)$ and $18.6 \%(p=0.0048)$. The embryonic lethality observed in $66 \mathrm{H}$ and $103 \mathrm{C}$ strains was mainly due to the EED phenotype, since respectively $10.5 \%$ and $11.8 \%(p=0.034)$ of the implanted embryos displayed at US2 the characteristic aspect of the ER. Conversely, $16.7 \%\left(p=6.25 \times 10^{-7}\right)$ of the implanted embryos in the 135B strain and $16.3 \%(p$ $=2.77 \times 10^{-10}$ ) in the $135 \mathrm{E}$ strain could rather be classified as LED, since the highest proportion of their ELR, could be observed at US3. Interestingly, in $66 \mathrm{H}$ and $103 \mathrm{C}$ the remaining fraction of the ELR ness. Thus, the embryo head was the last structure

We analyzed by ultrasound biomicroscopy a total of respec- 


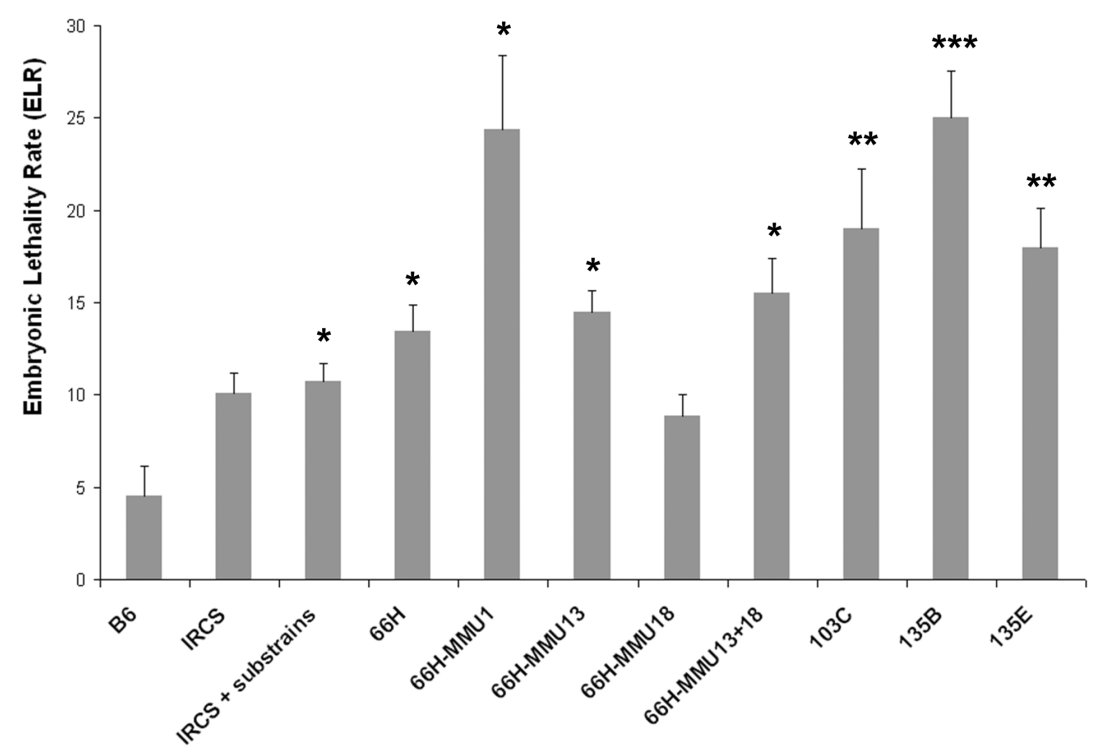

Fig. 2. Results of the interspecific recombinant congenic strain (IRCS) phenotyping in terms of Embryonic Lethality Rate (ELR) defined as the proportion of death embryos at any stage of development to the totality of implanted embryos. Results are presented as the average rate of dead embryos. Error bars correspond to SEM, calculated from the variation between individual females.
MMU1, MMU13 and MMU18 segments) was estimated at $4 \%$ (not significantly different from C57BL/ $6 \mathrm{~J})$. In contrast, LED was high in $66 \mathrm{H}-\mathrm{MMU} 1$ and $66 \mathrm{H}-\mathrm{MMU} 13$ (17.4\%, $\mathrm{p}=0.006$ and $10.2 \%$, $\mathrm{p}=0.0001$, respectively) suggesting an epistatic (protective?) effect of the 66H-MMU18 spretus fragment as shown in Table 2. In fact in the $66 \mathrm{H}$ strain, the presence of the three fragments was mainly associated with EED. This could indicate that the MMU18 segment encompasses genetic factors that promote embryonic resorption between E4.5 and E8.5 in the presence of factors expressed from $66 \mathrm{H}-\mathrm{MMU} 1$ and $66 \mathrm{H}-\mathrm{MMU} 13$ fragments. Other sub-strains containing different segment combinations were created from the F2 population. The $66 \mathrm{H}-\mathrm{MMU} 13+18$ substrain showed an increase in ELR $(16.7 \%, p=0.011)$ mainly represented by the LED phenotype. In this case the effect of MMU18 genetic composition seems not to enable to compensate the LED phenotype produced by the MMU13 spretus fragment. The $66 \mathrm{H}$ MMU1+MMU13 and 66H-MMU1+18 were not phenotyped as these strains are highly hypofertile in terms of mating difficulties (defined as the time necessary to became pregnant, Table 2). (represented by LED) also shown significant rates compared with the control group (66H-LED: $4 \%, \mathrm{p}=0.018)$, 103C-LED: $\left.7.8 \%, p=6.48 \times 10^{-5}\right)$. These findings are to be compared with the complete absence of the LED phenotype in the control group.

Genetically, the $66 \mathrm{H}$ strain encompasses three spretus genomic fragments located on chromosomes MMU1, MMU13 and MMU18. To precisely dissect the genotype/phenotype interaction, we created and phenotyped three substrains derived from $66 \mathrm{H}$ each containing a unique spretus fragment: $66 \mathrm{H}-\mathrm{MMU} 1$, $66 \mathrm{H}-\mathrm{MMU} 13$ and 66H-MMU18. Each fragment encompasses a unique chromosomal region present in the parental $66 \mathrm{H}$ strain. We observed an increase of the ELR in both 66H-MMU1 (24, 6 $\%, p=0,013)$ and $66 \mathrm{H}-\mathrm{MMU} 13(14,7 \%, \mathrm{p}=0,01)$ whereas in $66 \mathrm{H}-\mathrm{MMU} 18$ the lethality phenotype was absent.

Interestingly, the LED rate in $66 \mathrm{H}$ (containing the three

\section{Mapping of quantitative trait loci (QTL) involved in embry- onic resorption}

In our model, the significant phenotypic differences observed between the IRCS and the C57/ BL6 control group could be mapped to chromosomal fragments from Mus spretus located in the C57BL/6J genetic background. Therefore, these regions should contain genes responsible for the observed phenotype. Three QTL of embryonic lethality were finally unambiguously mapped on single chromosome segments from strains containing a unique spretusfragment $(66 \mathrm{H}-\mathrm{MMU} 13,66 \mathrm{H}-\mathrm{MMU} 1$ and 135E).

The $66 \mathrm{H}-\mathrm{MMU} 13$ spretus fragment $(\sim 3.4 \mathrm{Mb})$ is comprised between the rs120693734 and D13Mit47 polymorphic genetic markers. This relatively short chromosomal region (QTL-Led1) is responsible for the LED phenotype. This region contains 31 genes (Table 3). Among these, Btf3, PolK and Foxd1 are

TABLE 2

\section{STATISTICAL ANALYSIS FROM 39 OF THE 53 IRCS PHENOTYPED USING IN VIVO ULTRASOUND BIOMICROSCOPY}

\begin{tabular}{|c|c|c|c|c|c|}
\hline Strain & Average Implanted embryos ( \pm Stdev) & Embryonic resorption & Early Embryonic Death & Late Embryonic Death & Mating difficulty \\
\hline C57/BL6 & $8,9 \pm 1,2$ & $4,6 \%$ & $4,6 \%$ & $0 \%$ & $\Delta$ \\
\hline IRCS (whole set) & $8,2 \pm 1,9$ & $9,6 \%$ (NS) & $4,8 \%$ & $4,7 \%$ & $\Delta \boldsymbol{\Delta}$ \\
\hline IRCS (whole set + substrains) & $8,3 \pm 2$ & $10,5 \%(p=0,04)$ & $4,8 \%$ & $5,7 \%$ & $\Delta \boldsymbol{\Delta}$ \\
\hline $66 \mathrm{H}$ & $8,4 \pm 3,5$ & $14,5 \%(p=0,025)$ & $10,5 \%$ & $4 \%$ & $\Delta \boldsymbol{\Delta}$ \\
\hline 66H-MMU1 & $8,6 \pm 3$ & $24,6 \%(p=0,013)$ & $7,2 \%$ & $17,4 \%$ & $\boldsymbol{\Delta} \boldsymbol{\Delta} \boldsymbol{\Delta} \boldsymbol{\Delta}$ \\
\hline 66H-MMU13 & $8,8 \pm 2,1$ & $14,7 \%(p=0,01)$ & $4,5 \%$ & $10,2 \%$ & $\Delta$ \\
\hline 66H-MMU18 & $8,6 \pm 1$ & $8,3 \%$ (NS) & $6,7 \%$ & $1,6 \%$ & $\Delta \boldsymbol{\Delta}$ \\
\hline 66H-MMU13+18 & $7,3 \pm 2,5$ & $16,7 \%(p=0,011)$ & $4,6 \%$ & $12,1 \%$ & $\Delta \mathbf{\Delta}$ \\
\hline $103 C$ & $8,5 \pm 2,7$ & $19,6 \%(p=0,0012)$ & $11,8 \%$ & $7,8 \%$ & $\Delta \boldsymbol{\Delta}$ \\
\hline 135B & $8 \pm 2$ & $25 \%(p=0,0002)$ & $8,3 \%$ & $16,7 \%$ & $\Delta \boldsymbol{\Delta} \Delta$ \\
\hline 135E & $8,6 \pm 1,3$ & $18,6 \%(p=0,0048)$ & $2,3 \%$ & $16,3 \%$ & $\Delta \boldsymbol{\Delta}$ \\
\hline
\end{tabular}

The number of triangles represents mating difficulty in terms of period of time to obtain a gestation: $\boldsymbol{\Delta}$ : easy. $\boldsymbol{\Delta} \boldsymbol{\Delta}:$ mildly difficult. $\boldsymbol{\Delta} \boldsymbol{\Delta} \boldsymbol{\Delta}$ highly difficult. $\boldsymbol{\Delta} \boldsymbol{\Delta} \boldsymbol{\Delta}$ : very highly difficult. 
TABLE 3

\section{GENES LOCATED ON MMU13 BETWEEN RS120693734 AND D13MIT47 MARKERS}

\begin{tabular}{|c|c|c|c|c|}
\hline Start (bp) & End (bp) & Gene Symbol & Mutants with an effect on Embryonic letality & Gene Name \\
\hline 96702488 & 96719173 & F2R & Gene targeting & coagulation factor II (thrombin) receptor \\
\hline 97489065 & 97516268 & 1200014M14Rik & & RIKEN cDNA 1200014M14 gene \\
\hline 97517456 & 97536685 & 9330128J19Rik & & RIKEN cDNA 9330128J19 gene \\
\hline 97581386 & 97643184 & Polk & & polymerase (DNA directed), kappa \\
\hline 97643434 & 97738249 & Col4a3bp & & collagen, type IV, alpha 3 (Goodpasture antigen) binding protein \\
\hline 97750033 & 97771547 & Hmgcr & Gene targeting & 3-hydroxy-3-methylglutaryl-Coenzyme A reductase \\
\hline 98046888 & 98048213 & Gm73 & & gene model $73,(\mathrm{NCBI})$ \\
\hline 98122569 & 98135028 & 1700029F12Rik & & RIKEN cDNA $1700029 \mathrm{~F} 12$ gene \\
\hline 98172342 & 98230214 & B230112C05Rik & & RIKEN cDNA B230112C05 gene \\
\hline 98198909 & 98200046 & EG620648 & & predicted gene, EG620648 \\
\hline 98231080 & 98238565 & 5730427N09Rik & & RIKEN cDNA 5730427N09 gene \\
\hline 98238636 & 98277162 & Gfm2 & & G elongation factor, mitochondrial 2 \\
\hline 98277106 & 98298969 & Hexb & & hexosaminidase B \\
\hline 98341869 & 98353733 & Enc1 & & ectodermal-neural cortex 1 \\
\hline 98660157 & 98684151 & EG328314 & & predicted gene, EG328314 \\
\hline 98844851 & 98847536 & $5330416 \mathrm{C01Rik}$ & & RIKEN cDNA 5330416C01 gene \\
\hline 98860287 & 98860745 & ENSMUSG00000069117 & & predicted gene, ENSMUSG00000069117 \\
\hline 98999618 & 99306324 & Rgnef & & Rho-guanine nucleotide exchange factor \\
\hline 99347002 & 99363149 & Utp15 & & UTP15, U3 small nucleolar ribonucleoprotein, \\
\hline 99363348 & 99374073 & Ankra2 & & ankyrin repeat, family A (RFXANK-like), 2 \\
\hline 99380049 & 99393927 & EG667718 & & predicted gene, EG667718 \\
\hline 99402661 & 99407249 & ENSMUSG00000071224 & & predicted gene, ENSMUSG00000071224 \\
\hline 99410052 & 99417124 & Btf3 & Gene trap approach & Basic transcription factor 3 \\
\hline 99416579 & 99417461 & ENSMUSG00000048603 & & predicted gene, ENSMUSG00000048603 \\
\hline 99454399 & 99456860 & Foxd1 & Gene targeting & forkhead box D1 \\
\hline 99502252 & 99502685 & ENSMUSG00000059468 & & predicted gene, ENSMUSG00000059468 \\
\hline 99589690 & 99589980 & ENSMUSG00000071222 & & predicted gene, ENSMUSG00000071222 \\
\hline 99657899 & 99658521 & ENSMUSG00000068602 & & predicted gene, ENSMUSG00000068602 \\
\hline 99713670 & 99714225 & EG218501 & & predicted gene, EG218501 \\
\hline 99735135 & 99737495 & Tmem174 & & transmembrane protein 174 \\
\hline 99786395 & 99794988 & Tmem171 & & transmembrane protein 171 \\
\hline 99823567 & 99915303 & Fcho2 & & FCH domain only 2 \\
\hline 100524598 & 100616697 & Mtap1b & Gene targeting & microtubule-associated protein $1 \mathrm{~B}$ \\
\hline
\end{tabular}

In the $66 \mathrm{H}-\mathrm{MMU} 13$ substrain this region originates from Mus spretus.

transcriptions factors. It may be possible that their sequence or expression levels impair the normal transactivation of target genes involved in implantation and/or early development.

The significant increase in the LED phenotype frequency observed in the $66 \mathrm{H}-\mathrm{MMU} 1$ strain permitted us to define a second QTL. The 66H-MMU1 spretus fragment is delimited by D1Mit50 and rs120683504 markers corresponding to a large 18.3Mb region not shared with any other IRCS strain. This QTL region, named $L e d 2$, contains 215 genes (143 described and 72 predicted). The expressional profile analysis of these genes was assessed using the Symatlas gene expression database (http://symatlas.gnf.org) which showed that Bok, and Htr2b genes are strongly expressed in mouse placental tissue, while Sned1, and Gpc1 are highly expressed in uterus. Interestingly, Bok is also highly expressed in the ovary, arguing about a potential ovarian dysfunction in $66 \mathrm{H}-M M U 1$ substrain. Bok (Bcl-2 Related Ovarian Killer) is considered a pro-apoptotic factor (Hsu and Hsueh, 1998, Hsu et al., 1997, Rodriguez et al., 2006) supposedly implicated in ovarian cell apoptosis and atresia. Indeed, and conversely to $66 \mathrm{H}, 66 \mathrm{HMMU}-13$ and $66 \mathrm{HMMU}-18$, the $66 \mathrm{H}-\mathrm{MMU} 1$ substrain displayed a strong reproductive dysfunction in terms of pregnancy success as we obtained only 8 pregnant females during 9 months of mating cycles (Table 2). The MMU1 region matches with a previously described QTL involved in premature ovulation and primary oocyte arrest (Popoa), that was related with meiotic abnormalities in the LT/SvKau-derived alleles strains, located up to now to a $\sim 50 \mathrm{Mb}$ region (Everett et al., 2004).

We identified an additional QTL (Led3) located on MMU19 in $135 \mathrm{E}$ strain. This genomic region, encompassing $8 \mathrm{Mb}$, can be unambiguously associated with the phenotype of the 135E strain which carries a unique spretus fragment located between D19Mit49 and D19Mit137 markers.

The 135B strain encompasses two spretus fragments located on MMU12 (17.8 Mb, between D12Mit135 and rs120692608 markers) and MMU13 (8.8 Mb between rs120693763 and D13Mit32 markers). Although the 66H-MMU13 and 135B-MMU13 spretus fragments are not overlapping they are nearly contiguous (separated by a $40 \mathrm{~Kb}$ C57BL/6J genomic region). We could hypothesise that in the context of a spretus chromosomal continuity on MMU13, the presence of this C57BL/ $6 \mathrm{~J}$ "disruptive" region could interfere with a common regulatory region potentially linked with both $66 \mathrm{H}-\mathrm{MMU} 13$ and 135B LED phenotypes. In this context, the classical genetic approach to elucidate the unambiguous effect of a spretus fragment should consist on the separation of the 135B chromosomal fragments. 
Finally, we could detect a significant increase of the EED phenotype in the $103 \mathrm{C}$ strain. In this case, 4 spretus fragments are fixed on the C57BL/6J genetic background: MMU4 (between D4Mit34-rs120686944), MMU7 (between rs120688996rs120689110), MMU9 (between rs120690534- rs120690604) and MMU19 (between D19Mit32-rs120696784).

\section{Conclusion}

The use of IRCS to finely dissect genetic factors causing various phenotypes is appropriate for dissecting reproductive phenotypes, as shown in this study and the previous one using the same material for male phenotypes (L'Hote et al., 2007). This approach implicates extremely challenging successive mice crosses since IRCS are hypofertile. Indeed, during the IRCS strain production, more than $50 \%$ did not survive, suggesting that the genetic consequences of consanguinity or in many cases, the mingling of the Mus musculus and Mus spretusgenomes was not viable. The available IRCS mice survived only in the cases of favorable gene combinations. Thus, the totality of the 53 IRCS may harbour specific genome composition enabling them to have survived for at least 10 years. We can hypothesize that the embryonic resorption phenotype would have been originally present in a larger number of strains and that $66 \mathrm{H}, 103 \mathrm{C}, 135 \mathrm{~B}$ and $135 \mathrm{E}$ strains have been early preserved by genetic compensatory events.

Up to now, diverse mice crosses have shown high rate of embryonic resorption. For instance, the different mating combinations of $\mathrm{CBA} / 2 \mathrm{X} \mathrm{DBA} / 2$ mice display a natural resorption rate of about $20-40 \%$ and up to $60 \%$, if the females are injected with polyIC, a synthesized double-strand RNA able to activate natural killer (NK) cells (Shimada et al., 2003). Other studies showed that 15 to $20 \%$ of embryos undergo resorption in the spontaneous abortion murine model consisting of females CBA/2x males DBA/ $J$, in which an early infiltration of the decidua with macrophages expressing inducible nitric oxide synthase has been demonstrated (Haddad et al., 1995). Recently, Kaare et al. analysed the entire open reading frame of the AMN gene in patients affected with recurrent spontaneous abortion but no causal mutations could be associated (Kaare et al., 2006). This group based the candidate gene approach in the observation that a transgeneinduced insertion in the Amngene was prenatally lethal in mouse due to gastrulation defects (Wang et al., 1996) generating the embryonic resorption.

In conclusion, our study describes the first report of an in vivo approach of the embryonic development in order to identify genes responsible for complex phenotypic traits in mice. Furthermore, the IRCS model allowed us to propose a restricted number of candidate genes causing embryonic resorption. We believe that these results could be an important starting point in understanding the genetic aetiology of RSA.

\section{Materials and Methods}

\section{Animals}

The Interspecific Recombinant Congenic Strains used in the present study were produced from an initial cross between Mus spretus (SEG/ Pas, strain SEG) females and Mus musculus domesticus (C57BL/6J, strain B6) males, followed by three backcrosses of the $\mathrm{F} 1$ fertile males with $\mathrm{B} 6$ females and by at least 20 generations of brother/sister crosses
(Burgio et al., 2007, L'Hote et al., 2007). The map of the different strains is given at the Pasteur Institute Website: http://www.pasteur.fr/ip/index.jsp. Thus, each strain contains homozygous genomic fragments (in average $2 \%$ ) of Mus spretus included in a homozygous C57BL/6J genetic background $(\sim 98 \%)$. In order to create $66 \mathrm{H}$ substrains $(66 \mathrm{H}-\mathrm{MMU} 1,66 \mathrm{H}-$ MMU13 and $66 \mathrm{H}-\mathrm{MMU} 18), 66 \mathrm{H}$ female mice were crossed with $\mathrm{C} 57 \mathrm{BI} / 6$ males, then a F2 generation was produced. The progeny encompassing a unique spretus chromosomal fragment (MMU1, MMU13 or MMU18) was selected using microsatellites, amplified by a further B 6 cross and reestablished at the homozygous state by a brother/sister cross. Furthermore, during this process mice containing different allelic combinations were also generated $(66 \mathrm{H}-\mathrm{MMU} 1+13,66 \mathrm{H}-\mathrm{MMU} 1+18$ and $66 \mathrm{H}$ MMU13+18). The animals were bred in the Department of Mouse Functional Genetics of the Pasteur Institute (Paris). After weaning, 4 weeks aged mice were housed at the animal facilities of the Cochin Institute (Paris). Animals received food and water ad libitumand were exposed to a cycle of $12 \mathrm{~h}$ of light and $12 \mathrm{~h}$ of dark. Temperature was maintained at 20 degrees. In order to study embryo development and resorption, 8 to 12 week IRCS females were mated with C57BL/6J males, during a period of up to 4.5 days. Indeed, we could confirm that IRCS are intrinsically hypofertile showing a considerable enhancement of pregnancy rate from $10 \%$ to $40 \%$ when mated during 12 or 108 hours, respectively. All the experimental procedures were conducted in accordance with the policies of the Paris Descartes University, the Cochin Institute and the Guidelines for Biomedical Research Involving Animals.

\section{Ultrasound biomicroscopy and phenotyping}

Female mice ( $n=229$, Table 1$)$ were subjected to at least 3 ultrasonographic examinations, named consecutively ultrasonography 1 (US1) to ultrasonography 3 (US3), using the high frequency ultrasound system Vevo 770 (Visualsonics, Toronto, Canada). Searching to establish potential major anatomical anomalies of the vagina, the uterus and the ovaries, US1 was performed on every female during the morning of the first day of the breeding period initiation. US2 and US3 were performed for all pregnant mice, between E8.5-E12.5 and E10.5-E14.5, respectively. Additional examinations were assessed on the individuals affected by the Late Embryonic Death (LED) phenotype in order to follow the regressive process leading eventually to Embryonic Resorption (ER). In order to prepare the animals for ultrasound examination, anaesthesia was induced in a chamber and maintained with a face mask using 1.5\% of isoflurane (Minerve Veterinary Equipment, France). A chemical hair remover was used to eliminate the abdominal hair. The optimized contact between the skin surface and the transducer was obtained using an ultrasonographic contact gel. Body temperature, electrocardiographic and respiratory profiles were monitored using the Vevo 770's integrated heating pad and monitoring device. The ultrasound biomicroscope allows real time in vivo observations with a high resolution $(\sim 70 \mu \mathrm{m}$ and $\sim 40 \mu \mathrm{m}$ lateral and axial resolution, respectively) using high frequency transducers $(40-60 \mathrm{MHz})$. Real time visualisation was assessed at 40 frames/ minute. Searching the optimal image quality, RMV 704 and 708 transducers were used depending on the depth of each specific embryonic structure and the developmental stage.

\section{Statistical analysis}

The statistical value of the observed differences between the IRCS individuals and the control group (C57BL/6J) were evaluated by a student T-test corrected for multiple testing using the Bonferronni correction. Each female was analyzed separately; the variables observed were the number of implanted embryos, the number of dead embryos at US2 and US3, the position of implantation, the sex ratio of surviving pups at three days. Thus, $p<0.05$ was considered significant.

\section{Acknowledgements}

$P L$ is financed by the MAMMIFERT "Agence Nationale de la Recherche" grant. This work was funded by INSERM and by the MAMMIFERT 
grant. Isabelle Lanctin has been an invaluable contributor for mouse breeding at Pasteur Institute, and is greatly acknowledged.

\section{References}

ARTLEY, J.K., BRAUDE, P.R. and JOHNSON, M.H. (1992). Gene activity and cleavage arrest in human pre-embryos. Hum Reprod7: 1014-1021.

BURGIO, G., SZATANIK, M., GUENET, J.L., ARNAU, M.R., PANTHIER, J.J. and MONTAGUTELLI, X. (2007). Interspecific recombinant congenic strains between $\mathrm{c} 57 \mathrm{bl} / 6$ and mice of the mus spretus species: A powerful tool to dissect genetic control of complex traits. Genetics 177: 2321-2333.

DEY, S.K., LIM, H., DAS, S.K., REESE, J., PARIA, B.C., DAIKOKU, T. and WANG, H. (2004). Molecular cues to implantation. Endocr Rev25: 341-373.

EVERETT, C.A., AUCHINCLOSS, C.A., KAUFMAN, M.H., ABBOTT, C.M. and WEST, J.D. (2004). Genetic influences on ovulation of primary oocytes in It/sv strain mice. Reproduction 128: 565-571.

FOSTER, F.S., PAVLIN, C.J., HARASIEWICZ, K.A., CHRISTOPHER, D.A. and TURNBULL, D.H. (2000). Advances in ultrasound biomicroscopy. Ultrasound Med Bio/26: 1-27.

HADDAD, E.K., DUCLOS, A.J. and BAINES, M.G. (1995). Early embryo loss is associated with local production of nitric oxide by decidual mononuclear cells. $J$ Exp Med 182: 1143-1151.

HSU, S.Y. and HSUEH, A.J. (1998). Intracellular mechanisms of ovarian cell apoptosis. Mol Cel/ Endocrinol 145: 21-25.

HSU, S.Y., KAIPIA, A., MCGEE, E., LOMELI, M. and HSUEH, A.J. (1997). Bok is a pro-apoptotic bcl-2 protein with restricted expression in reproductive tissues and heterodimerizes with selective anti-apoptotic bcl-2 family members. Proc Natl Acad Sci USA 94: 12401-12406.

HUET-HUDSON, Y.M., ANDREWS, G.K. and DEY, S.K. (1989). Cell type-specific localization of c-myc protein in the mouse uterus: Modulation by steroid hormones and analysis of the periimplantation period. Endocrinology 125: 1683-1690.

JI, R.P. and PHOON, C.K. (2005). Noninvasive localization of nuclear factor of activated $t$ cells $\mathrm{c} 1-/$ - mouse embryos by ultrasound biomicroscopy-doppler allows genotype-phenotype correlation. JAm Soc Echocardiogr18: 1415-1421.

KAARE, M., PAINTER, J.N., ULANDER, V.M., KAAJA, R. and AITTOMAKI, K. (2006). Variations of the amnionless gene in recurrent spontaneous abortions. Mol Hum Reprod 12: 25-29.

KAARE, M., ULANDER, V.M., PAINTER, J.N., AHVENAINEN, T., KAAJA, R. and AITTOMAKI, K. (2007). Variations in the thrombomodulin and endothelial protein c receptor genes in couples with recurrent miscarriage. Hum Reprod22: 864-868.

L'HOTE, D., SERRES, C., LAISSUE, P., OULMOUDEN, A., ROGEL-GAILLARD, C., MONTAGUTELLI, X. and VAIMAN, D. (2007). Centimorgan-range one-step mapping of fertility traits using interspecific recombinant congenic mice. Genetics 176: 1907-1921.

LEVINE, J.S., BRANCH, D.W. and RAUCH, J. (2002). The antiphospholipid syndrome. N Engl J Med 346: 752-763.

LI, T.C., MAKRIS, M., TOMSU, M., TUCKERMAN, E. and LAIRD, S. (2002). Recurrent miscarriage: Aetiology, management and prognosis. Hum Reprod Update 8: 463-481.

LIM, H., SONG, H., PARIA, B.C., REESE, J., DAS, S.K. and DEY, S.K. (2002).
Molecules in blastocyst implantation: Uterine and embryonic perspectives. Vitam Horm 64: 43-76.

MONTAGUTELLI, X. and ABITBOL, M. (2004). [applications of congenic strains in the mouse]. Med Sci (Paris) 20: 887-893.

PARIA, B.C., LIM, H., WANG, X.N., LIEHR, J., DAS, S.K. and DEY, S.K. (1998). Coordination of differential effects of primary estrogen and catecholestrogen on two distinct targets mediates embryo implantation in the mouse. Endocrinology 139: 5235-5246.

PHILIPP, T., PHILIPP, K., REINER, A., BEER, F. and KALOUSEK, D.K. (2003). Embryoscopic and cytogenetic analysis of 233 missed abortions: Factors involved in the pathogenesis of developmental defects of early failed pregnancies. Hum Reprod 18: 1724-1732.

PLOUFFE, L., JR., WHITE, E.W., THO, S.P., SWEET, C.S., LAYMAN, L.C., WHITMAN, G.F. and MCDONOUGH, P.G. (1992). Etiologic factors of recurrent abortion and subsequent reproductive performance of couples: Have we made any progress in the past 10 years? Am J Obstet Gynecol 167: 313-320; discussion 320-321.

RAI, R. and REGAN, L. (2006). Recurrent miscarriage. Lancet 368: 601-611.

REY, E., KAHN, S.R., DAVID, M. and SHRIER, I. (2003). Thrombophilic disorders and fetal loss: A meta-analysis. Lancet 361: 901-908.

RODRIGUEZ, J.M., GLOZAK, M.A., MA, Y. and CRESS, W.D. (2006). Bok, bcl-2related ovarian killer, is cell cycle-regulated and sensitizes to stress-induced apoptosis. J Biol Chem 281: 22729-22735.

SALIM, R., REGAN, L., WOELFER, B., BACKOS, M. and JURKOVIC, D. (2003). A comparative study of the morphology of congenital uterine anomalies in women with and without a history of recurrent first trimester miscarriage. Hum Reprod 18: $162-166$.

SCHULTZ, R.M. (2002). The molecular foundations of the maternal to zygotic transition in the preimplantation embryo. Hum Reprod Update 8: 323-331.

SHARMA, N., LIU, S., TANG, L., IRWIN, J., MENG, G. and RANCOURT, D.E. (2006). Implantation serine proteinases heterodimerize and are critical in hatching and implantation. BMC Dev Bio/6: 61.

SHIMADA, S., IWABUCHI, K., WATANO, K., SHIMIZU, H., YAMADA, H., MINAKAMI, $\mathrm{H}$. and ONOE, K. (2003). Expression of allograft inflammatory factor-1 in mouse uterus and poly(i:C)-induced fetal resorption. Am J Reprod Immuno/50: 104112.

STEPHENSON, M.D., AWARTANI, K.A. and ROBINSON, W.P. (2002). Cytogenetic analysis of miscarriages from couples with recurrent miscarriage: A casecontrol study. Hum Reprod 17: 446-451.

TULPPALA, M., PALOSUO, T., RAMSAY, T., MIETTINEN, A., SALONEN, R. and YLIKORKALA, O. (1993). A prospective study of 63 couples with a history of recurrent spontaneous abortion: Contributing factors and outcome of subsequent pregnancies. Hum Reprod 8: 764-770.

WANG, H. and DEY, S.K. (2006). Roadmap to embryo implantation: Clues from mouse models. Nat Rev Genet 7: 185-199.

WANG, X., BORNSLAEGER, E.A., HAUB, O., TOMIHARA-NEWBERGER, C., LONBERG, N., DINULOS, M.B., DISTECHE, C.M., COPELAND, N., GILBERT, D.J., JENKINS, N.A. et al. (1996). A candidate gene for the amnionless gastrulation stage mouse mutation encodes a traf-related protein. Dev Bio/177: 274-290.

WILCOX, A.J., WEINBERG, C.R., O'CONNOR, J.F., BAIRD, D.D., SCHLATTERER, J.P., CANFIELD, R.E., ARMSTRONG, E.G. and NISULA, B.C. (1988). Incidence of early loss of pregnancy. N Eng/ J Med 319: 189-194. 


\section{Further Related Reading, published previously in the Int. J. Dev. Biol.}

See our recent Special Issue Fertilization, in honor of David L. Garbers and edited by Paul M. Wassarman and Victor D. Vacquier at: http://www.ijdb.ehu.es/web/contents.php?vol=52\&issue=5-6

See our Special Issue Mammalian Reproduction and Development, in honor of Ann McLaren and edited by Brigid Hogan at: http://www.ijdb.ehu.es/web/contents.php?vol=45\&issue=3

Gene mapping of sperm quality parameters in recombinant inbred strains of mice Aniela Golas, Anna Dzieza, Katarzyna Kuzniarz and Jozefa Styrna Int. J. Dev. Biol. (2008) 52: 287-293

From phenotypic to molecular polymorphisms involved in naturally occurring variation of plant development

Carlos Alonso-Blanco, Belén Mendez-Vigo and Maarten Koornneef Int. J. Dev. Biol. (2005) 49: 717-732

Genetic architecture of leaf morphogenesis in Arabidopsis thaliana

P Robles, JM Perez-Perez, H Candela, V Quesada, JM Barrero, S Jover-Gil, MR Ponce, JL Micol

Int. J. Dev. Biol. (2001) 45: S61-S62

Expression of the fibroblast activation protein during mouse embryo development. J Niedermeyer, P Garin-Chesa, M Kriz, F Hilberg, E Mueller, U Bamberger, W J Rettig and A Schnapp

Int. J. Dev. Biol. (2001) 45: 445-447

Inbreeding depression in Rosmarinus officinalis $L$.

PJ Hidalgo, JL Ubera

Int. J. Dev. Biol. (2001) 45: S43-S44

Preimplantation genetic diagnosis and embryo research-human developmental biology in clinical practice.

P Braude

Int. J. Dev. Biol. (2001) 45: 607-611

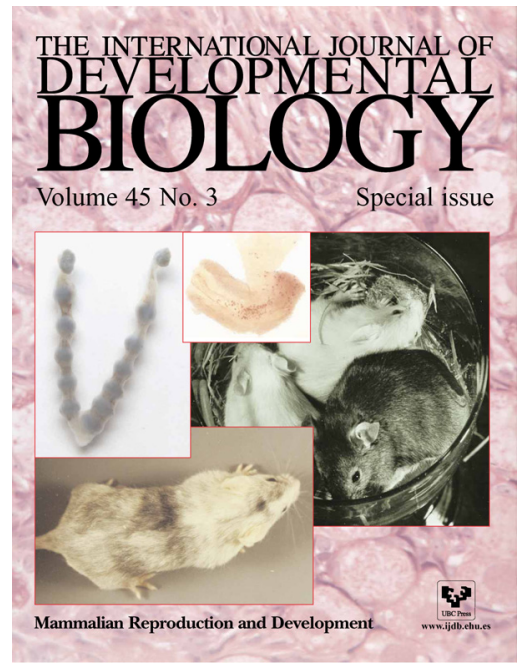

2006 ISI **Impact Factor $=3.577^{\star *}$

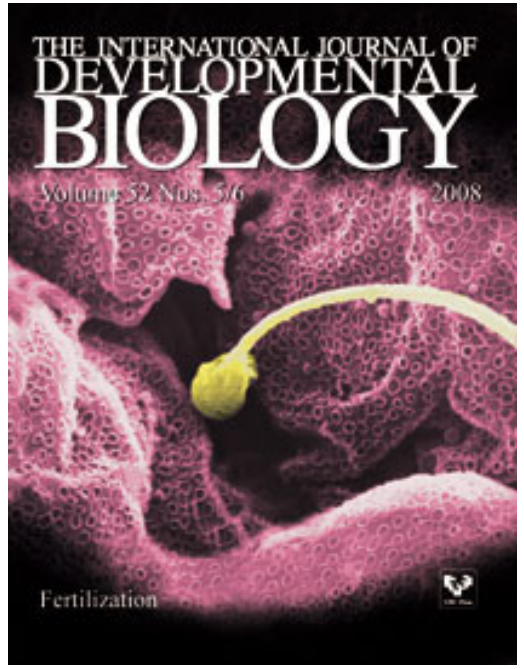

